<단보>

$$
\begin{gathered}
\text { 배합사료에 크릴, 켈프, 마늘 또는 } \\
\text { 감귤 분말 첨가가 넙치 육성어의 성장, } \\
\text { 혈액 성상 및 지방산 조성에 미치는 영향 }
\end{gathered}
$$

서주영·김 경덕 ${ }^{1}$ 손맹현 ${ }^{1}$ 이상민*

강릉원주대학교 해양생명공학부, ${ }^{1}$ 국립수산과학원 사료연구센터

\title{
Growth Performance, Hematological Parameter and Fatty Acid Composition of Growing Olive Flounder (Paralichthys olivaceus) to Dietary Inclusion of Kelp Meal, Krill Meal, Gartic Powder or Citrus Meal
}

\author{
Joo-Young Seo, Kyoung-Duck Kim¹, Maeng Hyun Son ${ }^{1}$ \\ and Sang-Min Lee* \\ Faculty of Marine Bioscience and Technology, Gangneung-Wonju National \\ University, Gangneung 210-702, Korea \\ ${ }^{1}$ Aquafeed Research Center, National Fisheries Research and Development \\ Institute, Pohang 791-923, Korea
}

This feeding experiment was conducted to investigate the effects of dietary inclusion of some additives on growth performance, hematological parameter and fatty acid composition of growing flounder. Triplicate groups of fish (average weight $120 \mathrm{~g}$ ) were fed one of five diets containing $5 \%$ kelp meal $(\mathrm{Ke}), 10 \%$ krill meal (Kr), 1\% garlic powder (Ga), 1\% citrus meal (Ci) or control diet (Con) without supplementation for 15 weeks. After the feeding experiment, survival was not significantly different among the groups fed the different diets. Weight gain of fish fed the Ci diet was significantly higher than that of fish fed the $\mathrm{Kr}$ diet, but not significantly different from $\mathrm{Con}, \mathrm{Ke}$ and $\mathrm{Ga}$ treatments. Feed efficiency and protein efficiency ratio of fish fed the Ga diet were significantly higher than those of fish fed the other diets. Total protein, glucose, GOT, GPT and total cholesterol contents in the plasma were not affected by the dietary additives. Composition of C20:4n-6 in the dorsal muscle of fish fed the Con diet was significantly higher than that of fish fed the other diets. The results of this study suggest that the dietary inclusion of garlic meal at $1 \%$ may improve feed utilization of growing flounder.

Key words: Growing flounder, Dietary additives, Growth, Hematological parameter, Fatty acid composition

서 론

우리나라 해산어 주요 양식 어류인 넙치의 배합사료를 개발 하기 위해 영양소 요구량 (Lee et al., 2000; Lee et al., 2002; Lee et al., 2003; Lee and Kim, 2005), 사료원료 이용성 (Yoo et al., 2006; Lee et al., 2008) 및 사료공급체계 (Seo et al., 2005)에 관한 연구들이 수행되었으며, 최근에는 배합사료와 생사료의 비교실험을 통해 배합사료의 우수성이 증명되고 있다 (Seo, et al., 2007; Kim et al., 2009). 하지만 배합사료가 양식 경영비에서 차지하는 높은 비중을 감안한다면, 대상종의 성장과 사료효율을 보다 향상시킬 수 있도록 배합사료의 조성 비를 지속적으로 개선하고 값비싼 영양소의 첨가수준을 최소 화하여 사료원가를 줄이는 등 배합사료의 품질 개선을 위한 연구는 지속되어야 한다.

어류의 성장을 증진시키거나 육질을 개선시키기 위한 연구 의 일환으로 효능이 있는 것으로 알려진 물질이나 원료를

\footnotetext{
*Corresponding author: smlee@gwnu.ac.kr
}

탐색하여 배합사료에 첨가하여 대상 어류의 성장, 사료효율 및 면역능력 등을 개선할 수 있는 가능성을 조사하는 것은 배합사료 품질 향상에 도움이 될 것으로 기대된다. 생약제 (Kim et al., 1998), 송강약돌 (Choi et al., 2004), 녹차 (Cho et al., 2006) 그리고 고추냉이 추출물 (Seo et al., 2009) 등이 넙치용 배합사료 첨가제로서 그 효능이 연구된 바 있다. 이러 한 첨가제 외에도 다양한 원료들을 대상으로 그 효능을 조사 하기 위한 연구들이 수행되고 있는데, 켈프는 항암, 항지혈 및 항산화 효능이 있으며 (Satoru et al., 2002; Heo et al., 2005), 마늘은 항균 (Chung et al., 2003), 항산화 (Yang, 2007) 및 콜레 스테롤 저하 (Youn et al., 1998) 등의 효능이, 감귤은 항산화 및 항균 효과 (Ahn et al., 2007)가 우수한 것으로 밝혀져 있다. 그리고 크릴은 어류의 기호성 향상에 효과가 있다고 보고된 바 있어 (Gaber, 2005), 이들 원료들은 넙치 육성용 사료 첨가제 로서 이용할 가치가 있을 것으로 보인다. 이러한 정보들을 바탕으로 본 연구는 배합사료에 분말형태의 켈프, 크릴, 마늘 
및 감귤의 첨가가 넙치 육성어의 성장, 혈액 성상 및 근육 지방산 조성에 미치는 영향을 조사하였다.

\section{재료 및 방법}

실험사료

Table 1에 나타낸 바와 같이, 실험사료의 주요 단백질원으 로 어분을 사용하였고, 탄수화물원으로 소맥분을, 지질원으로 오징어간유, 아마인유 및 대두유를 각각 사용하였다. 다양한 첨가제의 효과를 조사하기 위하여 대조사료 (Con)의 어분 대신 크릴분말 $(\mathrm{Kr}) 10 \%$, 소맥분 대신 켈프밀 $(\mathrm{Ke}) 5 \%$, 마늘분말 (Ga) $1 \%$ 및 감귤분말 $(\mathrm{Ci}) 1 \%$ 를 분말형태로 각각 첨가하여 총 5 종류의 실험사료를 설계하였다. 실험 사료에 사용된 첨가 제들은 시판되고 있는 것을 구입하였다. 설계된 사료 원료들을 잘 혼합한 후 원료 $100 \mathrm{~g}$ 당 물 $40 \mathrm{~g}$ 정도를 첨가하여 pellet 제조기로 압출성형 하였다. 제조된 실험사료는 실온에서 24시 간 건조한 후, $-30^{\circ} \mathrm{C}$ 에서 보관하면서 넙치에게 공급하였다.

Table 1. Composition of ingredients and proximate analysis of the experimental diets

\begin{tabular}{|c|c|c|c|c|c|}
\hline & \multicolumn{5}{|c|}{ Diets } \\
\hline & Con & $\mathrm{Ke}$ & $\mathrm{Kr}$ & $\mathrm{Ga}$ & $\mathrm{Ci}$ \\
\hline \multicolumn{6}{|l|}{ Ingredients (\%) } \\
\hline $\begin{array}{l}\text { Fish meal }(69.5 \% \mathrm{CP}, 8.3 \% \\
\mathrm{CL})\end{array}$ & 50.0 & 50.0 & 40.0 & 50.0 & 50.0 \\
\hline Wheat flour $(14.6 \% \mathrm{CP})$ & 27.71 & 22.71 & 27.71 & 26.71 & 26.71 \\
\hline Soybean meal $(53.6 \%$ CP) & 7.0 & 7.0 & 7.0 & 7.0 & 7.0 \\
\hline Wheat gluten $(83.7 \% \mathrm{CP})^{\prime}$ & 5.0 & 5.0 & 5.0 & 5.0 & 5.0 \\
\hline Beer yeast $(49.1 \% \mathrm{CP})$ & 2.0 & 2.0 & 2.0 & 2.0 & 2.0 \\
\hline Squid liver oil & 1.0 & 1.0 & 1.0 & 1.0 & 1.0 \\
\hline Linseed oil & 2.0 & 2.0 & 2.0 & 2.0 & 2.0 \\
\hline Soybean oil & 2.0 & 2.0 & 2.0 & 2.0 & 2.0 \\
\hline Vitamin premix ${ }^{1}$ & 1.5 & 1.5 & 1.5 & 1.5 & 1.5 \\
\hline Mineral premix ${ }^{2}$ & 1.5 & 1.5 & 1.5 & 1.5 & 1.5 \\
\hline Choline salt $(50 \%)$ & 0.1 & 0.1 & 0.1 & 0.1 & 0.1 \\
\hline Vitamin $\mathrm{E}$ & 0.04 & 0.04 & 0.04 & 0.04 & 0.04 \\
\hline Vitamin C & 0.15 & 0.15 & 0.15 & 0.15 & 0.15 \\
\hline Kelp meal $(13.6 \% \mathrm{CP})^{3}$ & & 5.0 & & & \\
\hline Krill meal $(66.4 \% \mathrm{CP})^{3}$ & & & 10.0 & & \\
\hline Garlic powder ${ }^{4}$ & & & & 1.0 & \\
\hline Citrus meal ${ }^{4}$ & & & & & 1.0 \\
\hline \multicolumn{6}{|c|}{ Proximate analysis (\%, dry matter basis) } \\
\hline Dry matter & 84.0 & 84.7 & 85.7 & 85.4 & 87.5 \\
\hline Crude protein & 49.2 & 49.4 & 48.1 & 49.3 & 49.0 \\
\hline Crude lipid & 10.0 & 10.0 & 10.5 & 10.3 & 10.3 \\
\hline Ash & 9.4 & 11.7 & 9.4 & 9.6 & 9.3 \\
\hline
\end{tabular}

${ }^{1}$ Vitamin premix contained the following amount which were diluted in cellulose ( $\mathrm{g} / \mathrm{kg}$ premix): Thiamin hydrochloride, 2.7; riboflavin, 9.1; pyridoxine hydrochloride, 1.8; niacin, 36.4; Ca-D-pantothenate, 12.7; myo-inositol, 181.8; Dbiotin, 0.27; folic acid, 0.68; p-aminobenzoic acid, 18.2; menadione, 1.8; retinyl acetate, 0.73 ; cholecalciferol, 0.003; cyanocobalamin, 0.003 .

${ }^{2}$ Mineral premix contained the following ingredients $(\mathrm{g} / \mathrm{kg}$ premix): $\mathrm{MgSO}_{4} \cdot 7 \mathrm{H}_{2} \mathrm{O}, 80.0 ; \mathrm{NaH}_{2} \mathrm{PO}_{4} \cdot 2 \mathrm{H}_{2} \mathrm{O}, 370.0 ; \mathrm{KCl}$, 130.0; Ferric citrate, $40.0 ; \mathrm{ZnSO}_{4} \cdot 7 \mathrm{H}_{2} \mathrm{O}, 20.0$; Ca-lactate, 356.5; $\mathrm{CuCl}, 0.2 ; \mathrm{AlCl}_{3} \cdot 6 \mathrm{H}_{2} \mathrm{O}, 0.15 ; \mathrm{KI}, 0.15 ; \mathrm{Na}_{2} \mathrm{Se}_{2} \mathrm{O}_{3}$, $0.01 ; \mathrm{MnSO}_{4} \cdot \mathrm{H}_{2} \mathrm{O}, 2.0 ; \mathrm{CoCl}_{2} \cdot 6 \mathrm{H}_{2} \mathrm{O}, 1.0$.

${ }^{3}$ Provided by Fisheries Co-op Feeds Co., Ltd. Gyeong-Nam province, Korea.

${ }^{4}$ Purchased in the market.

\section{실험어 및 사육관리}

경북 포항의 개인 양식장에서 넙치 육성어를 구입하여 강릉 원주대학교 해양생물연구교육센터로 수송한 후 상품사료로 2주간 예비 사육하였다. 사육실험은 무작위로 선별된 넙치 (평균체중 $120 \pm 4.6 \mathrm{~g}$ )를 총 15 개의 FRP 원형수조 $(300 \mathrm{~L})$ 에 20 마리씩 3 반복으로 수용하여 15 주간 수행하였다. 실험사료 는 1일 1회 (09:00) 실험어가 먹을 때 까지 만복으로 공급하였 다. 각 수조마다 약하게 폭기시켜 산소를 공급하였고, 여과된 자연해수를 각 실험수조마다 분당 $5 \mathrm{~L}$ 로 조절하여 흘려주었으 며, 사육기간 동안의 수온은 $20.9 \pm 1.2^{\circ} \mathrm{C}$ (평균士표준편차)였다. 그리고 사료공급 1 시간 후, 사육수를 환수시켜 배설물 및 찌꺼 기를 제거해 주었다.

\section{시료 채취 및 성분분석}

사육실험 시작시와 종료시에는 측정 전일 절식시킨 후 MS-222 $100 \mathrm{ppm}$ 수용액에 마취시켜 수조에 수용된 모든 실험 어의 무게를 측정하였다. 실험사료 및 근육의 조단백질 $(\mathrm{N} \times 6.25)$ 은 Auto Kjeldahl System (Buchi B-324/435/412, Switzerland)을 사용하여 분석하였고, 조지방은 ether를 사용하 여 추출하였으며, 수분은 $105^{\circ} \mathrm{C}$ dry oven에서 6 시간 동안 건조 후 측정하였고, 회분은 $600{ }^{\circ} \mathrm{C}$ 에서 4 시간 동안 태운 후 정량 하였다. 지방산 분석은 Folch et al. (1957)의 방법에 따라 클로 로포름과 메탄올 혼합액 (2:1)으로 총 지질을 추출하여 $14 \%$ $\mathrm{BF}_{3}-\mathrm{MeOH}$ (Sigma, MO, USA) 용액으로 지방산을 methylation 시킨 후, capillary column ( $\mathrm{SP}^{\mathrm{TM}}-2560,100 \mathrm{~m} \times 0.25 \mathrm{~mm}$ i.d., film thickness $0.20 \mu \mathrm{m}$, Supelco, PA, USA)이 장착된 gas chromatography (HP-6890N, Hewlett-Packard, CA, USA)로 지 방산을 분석하였다. Carrier gas는 헬륨을 사용하였으며, Oven 온도는 최초 $140^{\circ} \mathrm{C}$ 에서 $240^{\circ} \mathrm{C}$ 까지 $4^{\circ} \mathrm{C} / \mathrm{min}$ 씩 증가시켰다. 이 때, injector와 detector (FID) 온도는 $260^{\circ} \mathrm{C}$ 로 각각 설정하였으 며, 표준 지방산으로 37개 지방산 혼합물 (PUFA 37 Component FAME Mix, Supelco, PA, USA)을 사용하였다. 혈 액의 성상 변화를 조사하기 위해 각 실험구당 넙치를 5 마리씩 무작위로 추출하여 헤파린이 처리된 $3 \mathrm{ml}$ 주사기로 실험어의 미부 혈관에서 채혈하였으며, 원심분리 $(3,500 \mathrm{rpm}, 10$ 분)하여 얻은 혈장을 동결보존 $\left(-70^{\circ} \mathrm{C}\right)$ 하였다. 혈장내 total protein은 biuret법으로, glucose는 효소법으로, GOT와 GPT는 kinetic UV 법으로, total cholesterol은 COD-POD법을 사용하여 각각 분석 하였다.

\section{통계처리}

결과의 통계 처리는 SPSS Version 14.0 (SPSS, Michigan Avenue, Chicago, IL, USA) program을 사용하여 One-way ANOVA-test를 실시한 후, Duncan`s multiple range test (Duncan, 1955)로 평균간의 유의성을 검정하였다.

\section{결과 및 고찰}

평균 체중 $120 \mathrm{~g}$ 의 넙치 육성어를 15 주간 사육 실험한 결과 (Table 2), 생존율 (72-90\%)은 모든 실험구간에 유의한 차이가 
없었다. 증중율은 $\mathrm{Ci}$ 실험구가 $\mathrm{Kr}$ 실험구보다 유의하게 높았 으나 $(P<0.05)$, 다른 실험구와는 유의차가 없었다 $(P>0.05)$. 사료효율과 단백질 효율은 $\mathrm{Ga}$ 실험구가 다른 실험구에 비해 유의하게 높은 값을 보였으며, 일일사료섭취율은 $\mathrm{Ke}$ 실험구 에서 가장 높았고 $\mathrm{Ga}$ 실험구가 가장 낮은 값을 보였다. 비만도, 간 및 장 중량지수는 사료 첨가제에 영향을 받지 않았다 $(P>0.05)$. 이러한 결과는 본 연구에 사용된 첨가제가 넙치 육성어의 성장 개선에는 영향을 미치지 않는다는 것을 의미한 다. 반면에 마늘분 첨가 실험구의 경우, 다른 첨가제에 비해 넙치의 사료효율과 단백질 효율이 향상되는 것으로 나타났는 데, 이것은 마늘이 함유하고 있는 특정 성분이 넙치의 생리적 기능 향상에 도움이 된 것으로 생각된다. 기존의 연구 (Schram et al., 2008)에서 마늘분 첨가 사료를 공급한 catfish의 사료효 율이 향상되었으며, 어류 이외에도 육성 비육돈의 사료효율이 사료내 마늘분 첨가에 의해 향상된다고 보고되었다 (Kwon et al., 2005). 하지만, 본 연구에서 마늘분의 특정 함유성분과 사료 이용성의 상호작용에 관한 조사가 이루어지지 않았으므 로, 향후 이에 대한 상세한 연구가 필요할 것이다.

대조구와 유의한 차이는 없었지만, 감귤을 첨가한 실험구 가 가장 양호한 성장을 보였는데, 이것은 감귤이 함유하고 있는 유기산, 비타민, 베타카로틴 및 플라보노이드 등의 생리 활성물질 (Jeong et al., 1997; Miyaki et al., 1998)에 의한 영향으 로 판단된다. Song et al. (2002)은 사료에 감귤 발효액 첨가로 넙치의 성장이 향상되는 경향을 보인다고 보고하였다.

Table 2. Growth performance and feed utilization of growing flounder fed the experimental diets for 15 weeks ${ }^{1}$

\begin{tabular}{|c|c|c|c|c|c|}
\hline & \multicolumn{5}{|l|}{ Diets } \\
\hline & Con & $\mathrm{Ke}$ & $\mathrm{Kr}$ & $\mathrm{Ga}$ & $\mathrm{Ci}$ \\
\hline Initial weight (g/fish) & $122+25$ & $9 \pm 0.6$ & $119 \pm 4.9$ & $21 \pm 3.0$ & $121 \pm 2.1$ \\
\hline urvival (\%) & $72 \pm 9.3$ & $90 \pm 2.9$ & $75 \pm 5.0$ & $80 \pm 10.0$ & $75 \pm 13.2$ \\
\hline Weight gain $(\%)^{2}$ & $207 \pm 6.6^{\mathrm{ab}}$ & $220 \pm 7.2^{\mathrm{ab}}$ & $193 \pm 9.7^{\mathrm{a}}$ & $218 \pm 1.5^{\mathrm{ab}}$ & $237 \pm 15.0^{b}$ \\
\hline Feed efficiency $(\%)^{3}$ & $103 \pm 5.8^{\mathrm{a}}$ & $112 \pm 3.1^{\mathrm{a}}$ & $107 \pm 1.1^{\mathrm{a}}$ & $127 \pm 2.9^{b}$ & $113 \pm 2.2^{\mathrm{a}}$ \\
\hline Daily feed intake $(\%)^{4}$ & $0.69 \pm 0.03^{\mathrm{ab}}$ & $0.76 \pm 0.02^{b}$ & $0.67 \pm 0.01^{a b}$ & $0.63 \pm 0.04^{a}$ & $0.68 \pm 0.04^{\mathrm{ath}}$ \\
\hline Protein efficiency ratio ${ }^{5}$ & $2.5 \pm 0.14^{\mathrm{a}}$ & $2.7 \pm 0.13^{\mathrm{a}}$ & $2.6 \pm 0.04^{\mathrm{a}}$ & $3.1 \pm 0.12^{b}$ & $2.7 \pm 0.10^{\mathrm{a}}$ \\
\hline Condition $\mathrm{f}$ & $1.21 \pm 0.04$ & $1.12 \pm 0.07$ & $1.20 \pm 0.02$ & $1.21 \pm 0.06$ & $1.14 \pm 0.01$ \\
\hline Hepatosomatic index ${ }^{7}$ & $1.97 \pm 0.07$ & $1.62 \pm 0.15$ & $1.1 \angle I U .00$ & $1.22 \pm 0.35$ & $1.68 \pm 0.08$ \\
\hline Visceralsomatic index $^{8}$ & $2.18 \pm 0.14$ & $2.15 \pm 0.06$ & $1.90 \pm 0.07$ & $1.86 \pm 0.23$ & $2.08 \pm 0.04$ \\
\hline
\end{tabular}

${ }^{1}$ Values (mean \pm SE of three replication groups) in the same row not sharing a common superscript are significantly different $(P<0.05)$.

2 (Final fish wt. - initial fish wt.) $\times 100 /$ initial fish wt..

3 (Weight gain $\times 100$ ) $/$ feed intake (dry matter).

4 Feed intake (dry matter) $\times 100 /[$ (initial fish wt. + final fish wt. + dead fish wt.) $\times$ days $\mathrm{fed} / 2]$.

${ }^{5}$ Weight gain/protein intake.

${ }_{7}^{6}$ Fish wt. $\times 100 /$ total body length ${ }^{3}$.

7 Liver wt. $\times 100 /$ body weight.

${ }^{8}$ Viscera wt. $\times 100 /$ fish weight.
Table 3. Hematological change of the plasma in growing flounder fed the experimental diets for 15 weeks

\begin{tabular}{lccccc}
\hline Diets & $\begin{array}{c}\text { Total protein } \\
(\mathrm{g} / \mathrm{dL})\end{array}$ & $\begin{array}{c}\text { Glucose } \\
(\mathrm{mg} / \mathrm{dL})\end{array}$ & $\begin{array}{c}\text { GOT } \\
(\mathrm{IU} / \mathrm{L})\end{array}$ & $\begin{array}{c}\text { GPT } \\
(\mathrm{IU} / \mathrm{L})\end{array}$ & $\begin{array}{c}\text { Total cholesterol } \\
(\mathrm{mg} / \mathrm{dL})\end{array}$ \\
\hline $\mathrm{Con}$ & $4.2 \pm 0.14$ & $36 \pm 6.0$ & $6.0 \pm 0.4$ & $2.0 \pm 0.1$ & $216 \pm 5.8$ \\
$\mathrm{Ke}$ & $4.2 \pm 0.14$ & $30 \pm 2.2$ & $6.0 \pm 0.0$ & $2.0 \pm 0.1$ & $213 \pm 8.2$ \\
$\mathrm{Kr}$ & $4.4 \pm 0.18$ & $30 \pm 1.6$ & $5.8 \pm 0.3$ & $2.0 \pm 0.1$ & $232 \pm 11.7$ \\
$\mathrm{Ga}$ & $4.2 \pm 0.11$ & $24 \pm 1.5$ & $5.3 \pm 0.3$ & $2.0 \pm 0.1$ & $219 \pm 0.9$ \\
$\mathrm{Ci}$ & $4.4 \pm 0.05$ & $31 \pm 2.8$ & $5.8 \pm 0.3$ & $2.3 \pm 0.5$ & $222 \pm 5.4$ \\
\hline
\end{tabular}

${ }^{1}$ Values (mean \pm SE of three replication groups) in the same column not sharing a common superscript are significantly different $(P<0.05)$.

Table 4. Fatty acids (\% of total fatty acids) and crude lipid (\% of dry matter basis) compositions of dorsal muscle of growing flounder fed experimental diet for 15 weeks $^{1}$

\begin{tabular}{cccccc}
\hline & \multicolumn{5}{c}{ Diets } \\
\cline { 2 - 6 } Fatty acids & Con & $\mathrm{Ke}$ & $\mathrm{Kr}$ & $\mathrm{Ga}$ & $\mathrm{Ci}$ \\
\hline $\mathrm{C} 14: 0$ & $1.5 \pm 0.1^{\mathrm{a}}$ & $1.5 \pm 0.1^{\mathrm{a}}$ & $2.2 \pm 0.1^{\mathrm{b}}$ & $1.4 \pm 0.2^{\mathrm{a}}$ & $1.7 \pm 0.1^{\mathrm{a}}$ \\
$\mathrm{C} 16: 0$ & $24.8 \pm 1.3$ & $25.0 \pm 0.8$ & $26.4 \pm 0.3$ & $25.0 \pm 0.8$ & $25.2 \pm 0.3$ \\
$\mathrm{C} 16: 1$ & $0.9 \pm 0.5$ & $0.6 \pm 0.1$ & $0.8 \pm 0.1$ & $0.6 \pm 0.1$ & $0.9 \pm 0.2$ \\
$\mathrm{C} 18: 0$ & $0.5 \pm 0.1$ & $2.8 \pm 1.9$ & $0.9 \pm 0.1$ & $1.3 \pm 0.2$ & $1.7 \pm 0.4$ \\
$\mathrm{C} 18: 1 \mathrm{n}-9$ & $9.6 \pm 2.3$ & $7.8 \pm 0.2$ & $7.3 \pm 0.5$ & $7.1 \pm 0.2$ & $6.4 \pm 0.8$ \\
$\mathrm{C} 18: 2 \mathrm{n}-6$ & $17.2 \pm 0.7$ & $17.5 \pm 0.4$ & $18.7 \pm 0.7$ & $17.6 \pm 0.6$ & $18.4 \pm 0.1$ \\
$\mathrm{C} 18: 3 \mathrm{n}-3$ & $7.5 \pm 0.4$ & $6.7 \pm 0.3$ & $7.2 \pm 0.7$ & $8.7 \pm 3.0$ & $7.4 \pm 0.2$ \\
$\mathrm{C} 20: 4 \mathrm{n}-6$ & $2.0 \pm 0.1^{\mathrm{c}}$ & $0.6 \pm 0.1^{\mathrm{ab}}$ & $0.6 \pm 0.1^{\mathrm{ab}}$ & $0.5 \pm 0.1^{\mathrm{a}}$ & $1.2 \pm 0.3^{\mathrm{b}}$ \\
$\mathrm{C} 20: 5 \mathrm{n}-3$ & $5.0 \pm 0.2$ & $5.1 \pm 0.3$ & $5.4 \pm 0.1$ & $5.2 \pm 0.5$ & $5.6 \pm 0.1$ \\
$\mathrm{C} 22: 6 \mathrm{n}-3$ & $31.0 \pm 2.3$ & $32.4 \pm 1.3$ & $30.6 \pm 1.4$ & $32.7 \pm 1.2$ & $31.5 \pm 0.9$ \\
$\mathrm{n}-3 \mathrm{HUFA}$ & $36.0 \pm 2.1$ & $37.5 \pm 1.3$ & $36.0 \pm 1.5$ & $39.9 \pm 1.3$ & $37.2 \pm 0.8$ \\
\hline Crude lipid & $2.7 \pm 0.67$ & $3.7 \pm 0.56$ & $2.7 \pm 0.44$ & $3.7 \pm 0.93$ & $3.4 \pm 0.86$ \\
\hline 1 & Values (mean $\pm \mathrm{SE}$ of three replication groups) in the same \\
row not sharing a common superscript are significantly \\
different $(P<0.05)$.
\end{tabular}

배합사료에 켈프밀 첨가는 넙치의 성장과 사료효율에 영향 을 미치지 않은 것으로 나타나, 넙치 치어를 대상으로 수행된 연구결과 (Kim and Lee, 2008)와 유사하였다. 그러나 참돔의 경우, 사료에 5\% 켈프 첨가 (Nakagawa et al., 1997)로 성장이 향상된 반면, $10 \%$ 이상 첨가 (Yone et al., 1986)는 오히려 참돔의 성장에 부정적인 영향을 미칠 수 있다는 상반된 연구 결과가 보고된 바 있다.

크릴이 어류의 성장 개선에 효과적이라는 이전 연구결과 (Gaber, 2005)와는 달리 본 연구에서 넙치의 성장과 사료효율 개선에 도움이 되지 않는 것으로 나타났다. 이러한 결과들은 대상종 및 사용된 사료 원료나 조성비에 따라 첨가제의 효능 이 달라질 수 있다는 것을 의미하며, 첨가제 사용시 이에 대한 고려가 수반되어야 할 것이다.

사육실험 종료 후, 어체의 미부동맥에서 채혈한 혈액의 성 상을 Table 3에 나타내었다. Total protein (4.2-4.4 g/dL), glucose $(24-36 \mathrm{mg} / \mathrm{dL})$ 및 total cholesterol $(213-232 \mathrm{mg} / \mathrm{dL})$ 함량과 간 건강 지표로 사용되는 GOT (5.3-6.0 IU/L) 및 $\mathrm{GPT}$ 
(2.0-2.3 IU/L) 함량 모두 실험구간에 유의한 차이를 보이지 않았다 $(P>0.05)$. 아직까지 정상범위에 해당하는 혈액성상의 값들이 어종별로 확립되어 있지 않기 때문에 사용된 첨가제의 효능을 혈액학적으로 정확히 파악하기는 어렵지만, 본 연구에 사용된 첨가제는 넙치 육성어의 생리기능에 부정적인 반응을 보이지 않는 것으로 판단된다. 그리고 어류의 혈중 성분은 환경조건이나 건강상태에 따라 달라질 수 있기 때문에 혈액의 화학성분을 분석하기 위해서는 이에 대한 고려가 필요할 것이 다. Table 4에 나타낸 바와 같이, 등근육의 C14:0와 C20:4n-6 함량은 $\mathrm{Kr}$ 과 $\mathrm{Con}$ 실험구에서 각각 가장 높게 나타났으나, 그 외의 지방산 함량과 지질 함량은 사료 첨가제에 영향을 받지 않았다 $(P>0.05)$.

본 연구에 사용된 첨가제들은 넙치 육성어의 성장, 혈액성 상 및 체성분에 영향을 미치지 않았다. 이는 대조사료가 넙치 의 영양소 요구를 충족시켰기 때문에 본 연구에 사용된 각 첨가제의 효과가 없을 수 있음을 암시하고 있다. 또한, 모든 사료의 사료효율이 $100 \%$ 이상으로 높게 나타난 것으로 보아, 대조사료의 효능이 높음을 알 수 있다. 이러한 결과는 넙치사 료 관련 업계에서 배합사료 조성시 본 연구에 사용된 첨가제 들을 첨가할 필요가 없음을 암시하기 때문에 그 만큼 사료 단가를 낮출 수 있는 유익한 정보가 될 것으로 전망된다.

$$
\text { 사 사 }
$$

본 연구는 국립수산과학원 (고효율 배합사료 개발 및 실용 화 연구, RP-2010-AQ-023)의 연구비 지원에 의한 것이며, 이에 감사드립니다.

\section{참고문헌}

Ahn MS, Kim HJ and Seo MS. 2007. A study on the antioxidative and antimicrobial activities of the Citrus Unshju peel extracts. Kor J Food Culture 22, 454-461.

Cho SH, Lee SM, Park BH, Ji SC, Kwon MG, Kim YC, Lee JH, Park SG and Han HK. 2006. Effects of dietary inclusion of various sources of green tea on immune system and challenging test of juvenile olive flounder Paralichthys olivaceus. J Aquacult 19, 84-89.

Choi SM, Ko SH, Park GJ, Lim SR, Yu GY, Lee JH and Bai SC. 2004. Utilization of Song-Gang stone as the dietary additive in juvenile olive flounder, Paralichthys olivaceus. J Aquacult 17, 39-45.

Chung KS, Kang S and Kim JY. 2003. The antibacterial activity of garlic juice against pathogenic bacteria and lactic acid bacteria. Kor J Microbiol Biotechnol 31, 32-35.

Duncan DB. 1955. Multiple-range and multiple F tests. Biometrics 11, 1-42.

Folch J, Lees M and Stanley GHS. 1957. A simple method for the isolation and purification of total lipids from animal tissues. J Biol Chem 226, 496-509.

Gaber MMA. 2005. The effect of different levels of krill meal supplementation of soybean-based diets on feed intake, digestibility, and chemical composition of juvenile nile tilapia Oreochromis niloticus, L. J World Aquacult Soc 36, 346-353.

Heo SJ, Park PJ, Park EJ, Cho SK, Kim SK and Jeon YJ. 2005. Antioxidative effcect of proteolytic hydrolysates from Ecklonia cava on radical scavenging using ESR and H2O2-induced DNA damage. Food Sci Biotechnol 14, 614-620.

Jeong WS, Park SW and Chung SK. 1997. The antioxidative activity of Korean Citrus Unshiu peels. food Biotechnol 6, 292-296.

Kim DS, Kim JH, Jong CH, Lee SY, Lee SM and Moon YB. 1998. Utilization of obosan (dietary herbs) I . Effects on survival, growth, feed conversion ratio and condition factor in olive flounder, Paralichthys olivaceus. J Aquacult 11, 213-221.

Kim KD, Kang YJ, Lee HY, Kim KW, Jang MS, Kim SK and Son MH. 2009. Evaluation of extruded pellets containing different protein and lipid levels, and raw fish-based moist pellet for growth of flounder (Paralichthys olivaceus). Kor J Fish Aquat Sci 42, 476-480.

Kim SS and Lee KJ. 2008. Effects of dietary kelp (Ecklonia cava) on growth and innate immunity in juvenile olive flounder Paralichthys olivaceus. Aquacult Res 38, 1687-1690.

Kwon OS, Cho JH, Min BJ, Kim HJ, Chen YG, Yoo JS, Kim IH, La JC and Park HK. 2005. Effect of supplemental medicinal plants (Artemisia, Acanthopanax and Garlic) on growth performance, IGF-1 and meat quality characteristics in growing-finishing pigs. Korean J Food Sci Ani Resour 25, 316-321.

Lee SM and Kim KD. 2005. Effect of various levels of lipid exchanged with dextrin at different protein level in diet on growth and body composition of juvenile flounder Paralichthys olivaceus. Aquacult Nutr 11, 435-442.

Lee SM, Cho SH and Kim KD. 2000. Effects of dietary protein and energy levels on growth and body composition of juvenile flounder (Paralichthys olivaceus). J World Aquacult Soc 31, 306-315.

Lee SM, Kim KD and Lall SP. 2003. Utilization of glucose, maltose, dextrin and cellulose by juvenile flounder (Paralichthys olivaceus). Aquaculture 221, 427-438. 
Lee SM, Park CS and Bang IC. 2002. Dietary protein requirement of young Japanese flounder Paralichthys olivaceus fed isocaloric diets. Fish Sci 68, 158-164.

Lee SM, Seo JY, Choi KH and Kim KD. 2008. Apparent amino acid and energy digestibilities of common feed ingredients for flounder Paralichthys olivaceus. J Aquacult 21, 89-95.

Miyake T, Yamamoto K, tsujihara N and Osawa T. 1998. Protective effect of lemon flavonoids on oxidative stress in diabetic rats. Lipids, 32, 689-695.

Nakagawa H. Unimo T and Tasaka Y. 1997. Usefulness of Ascophyllum nodosum as a feed additive for red sea bream, Pagrus major. Aquaculture 151, 275-281.

Satoru K, Noboru T, Hiroo N, Shinji S and Hiroshi S. 2002. Oversulfation of fucoidan enhances its anti-angiogenic and antitumor activities. Biochem Pharmcol 34, 173-179.

Schram E, Pedrero Z, Cámara C, Van der Heul JW and Luten JB. 2008. Enrichment of African catfish with functional selenium originating from garlic. Aquacult Res 39, 850-860.

Seo JY, Choi J, Lee JH and Lee SM. 2007. Development of extruded pellet for growth of flounder (Paralichthys olivaceus) in commercial scale feeding trials. J Aquacult 20, 114-120.

Seo JY, Choi KH, Choi J and Lee SM. 2005. Effect of feeding frequency of extruded diets containing different macro-nutrient levels on apparent nutrient digestibility in grower flounder Paralichthys olivaceus. J Aquacult 18, 160-166.
Seo JY, Kim KD, Shin IS, Choi KD and Lee SM. 2009. Effects of supplemental dietary wasabi extract, chitosan and Pophyra on growth and body composition of juvenile flounder, Paralichthys olivaceus. Kor J Fish Aquat Sci 42, 257-261.

Song YB, Moon SW, Kim SJ and Lee YD. 2002. Effect of EM-fermented orange in commercial diet on growth of juvenile flounder, Paralichthys olivaceus. J Aquacult 15, 103-110.

Yang ST. 2007. Antioxidant activity of extracts of aged black garlic on oxidation of human low density lipoprotein. J Life Sci 17, 1330-1336.

Yone Y, Furuichi M and Urano K. 1986. Effects of dietary wakame Undaria penatifida and Ascophyllum nodosum supplements on growth, feed efficiency, and proximate compositions of liver and muscle for red sea bream. Nipp Suisan Gakka 52, 1465-1468.

Yoo GY, Choi SM, Kim KW and Bai SC. 2006. Apparent protein and phosphorus digestibilities of nine different dietary protein sources and their effects on growth of juvenile olive flounder, Paralichthys olivaceus. J Aquacult 19, 254-260.

Youn BS, Chae HS, Kim SC, Kim DW, Ahn CN and Kim YK. 1998. Effects of garlic feeding on laying hen. Kor J Ani Nut Feed 22, 357-362.

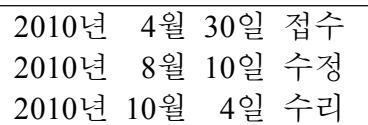

2010년 10월 4일 수리 